\title{
KOMODIFIKASI KONTEN HUMOR DALAM PROGRAM YUK KEEP SMILE DI TRANS TV
}

\author{
Formas Juitan Lase \\ formasjuitan@gmail.com \\ Program Studi Magister Ilmu Komunikasi \\ Universitas Diponegoro, Semarang
}

\begin{abstract}
One of mass media functions is entertainment; it is about diversion to distract attention from daily routine through entertainment television program. However, this function is neglected when commodification through logical capitalistic applied to obtain high shared rating. Yuk Keep Smile entertainment program is one of commodification through slapstick humor content, it is attacking and demeaning other people. This study is using Political Economy Media Theory focussing on commodification to analyze how the content of Yuk Keep Smile entertainment program is applying logical capitalistic to obtain high shared rating and ignoring the quality of it.
\end{abstract}

Keywords: Political Economy Media, Commodification, Rating, Humor

\begin{abstract}
Abstrak
Salah satu fungsi media massa adalah menjalankan fungsi hiburan yakni diversi untuk mengalihkan perhatian seseorang dari rutinitas sehari-hari melalui tayangan hiburan di televisi. Namun, fungsi ini menjadi terabaikan ketika sebuah tayangan dikemas dalam logika kapitalistik melalui praktik komodifikasi untuk memperoleh rating dan share yang tinggi. Program hiburan Yuk Keep Smile merupakan salah satu yang melakukan praktik komodifikasi melalui konten humor slapstik, saling menyerang dan merendahkan orang lain. Tulisan ini menggunakan Teori Ekonomi Politik Media yang fokus pada komodifikasi untuk menganalisis bagaimana konten-konten hiburan Yuk Keep Smile dikomodifikasi berdasarkan logika kapitalistik untuk memperoleh rating dan share yang tinggi, sementara kualitas konten diabaikan.
\end{abstract}

Kata kunci: Ekonomi Politik Media, Komodifikasi, Rating, Humor

\section{Pendahuluan}

Wright (dalam Ruben \& Stewart, 2006, h. 368-369) menyebutkan bahwa media massa memiliki beberapa fungsi yaitu, fungsi pengawasan (surveillance), korelasi (correlation), sosialisasi (socialization), dan hiburan (entertainment). Secara normatif keempat fungsi ini seharusnya dijalankan secara bersamaan oleh media massa dalam porsi yang seimbang.

Namun, jika dicermati fungsi hiburan menjadi yang paling dominan dari keseluruhan program televisi karena daya jualnya kepada khalayak jauh lebih tinggi berdasarkan indikator rating dan share yang diperoleh stasiun televisi. Karena semakin tinggi rating dan share yang dihasilkan sebuah 
program maka akan semakin banyak iklan yang masuk.

McQuail (2011, h.244) mengatakan bahwa, "Bisnis media bukan bisnis biasa." Aktivitas media tidak bisa dilepaskan dari kepentingan ekonomi maupun kepentingan politik yang bertarung di dalamnya. Media secara umum beroperasi menurut dikte ekonomi pasar. Itu sebabnya media harus menyesuaikan produknya sesuai selera pasar. Program-program itu kemudian dijalankan dengan cara-cara yang hegemonik dan eksploitatif dengan tujuan menciptakan potensi ekonomi media.

Kondisi ini menjadikan televisi bertingkah lebih brutal karena keseluruhan materi program bisa disulap dalam beragam jenis bahkan kekerasan sekalipun bisa dijadikan komoditas dagangan. Hal inilah yang terjadi dengan program acara Yuk Keep Smile (YKS) yang ditayangkan oleh stasiun televisi swasta Trans TV. Materimateri program yang ditayangkan di YKS mengundang penolakan dari masyarakat karena mengandung kekerasan, konten humor yang kasar hingga goyangan erotis.

Sebelumnya, program YKS yang bermetamorfosis dari program acara Ramadhan berjudul "Yuk Kita Sahur" mendapat animo yang besar dari masyarakat sehingga penayangannya yang semula dua kali seminggu menjadi tayang setiap hari, dan ditempatkan pada jam primetime. Secara sepintas, tidak ada yang salah dari ide kreatif YKS, karena konsepnya digagas untuk tujuan hiburan.

Namun, program YKS semakin hari semakin mengkhawatirkan. Pada beberapa tayangan mulai menunjukkan humor-humor yang sarkastik, adeganadegan kekerasan baik secara fisik maupun simbolik, dan berbagai goyangan yang menonjolkan sisi erotis. Adegan-adegan semacam ini dikeluhkan oleh masyarakat, sehingga menimbulkan berbagai protes. Rifqi yang menulis di laman change.org mangatakan,

“Acara komedi (Yuk Keep Smile) sangat tidak berkualitas dengan kata-kata kasar, menyiksa orang (entah itu main tebak-tebakan dengan kaki dimasukkan air es atau menyumpal tepung ke mulut lawan), sampai dengan goyangan tidak jelas yang dilaksanakan full 1 jam dan tidak berubah selama beberapa bulan terakhir, apalagi goyangannya memakai latar musik yang liriknya vulgar serta mengarah ke gerakan vulgar pula." (solopos.com, 3 Januari 2014).

Tak hanya itu, protes lain muncul dari pemerhati anak, Seto Mulyadi yang menilai program yang dibawakan artis Olga Syahputra, Raffi Ahmad, Adul, Soimah, Denny dan Wendy cagur, sudah sangat memprihatinkan dan merusak mental anak. Seto tidak melihat ada sedikit pun nilai edukasi yang diberikan meski tayang berjam-jam. "Saya juga dari awal protes keras dengan acara itu. Tidak edukatif, sampai ada anak-anak kecil juga ikut di acara itu," kata Seto (merdeka.com, Senin, 30 Desember 2013).

Protes pun dialamatkan kepada Komisi Penyiaran Indonesia (KPI) untuk segera menegur ataupun menutup acara tersebut. Hal yang diprotes terutama terkait goyang oplosan yang dipopulerkan oleh Soimah (Okezone.com, 31 Desember 2013). KPI menyebutkan sepanjang tahun 2013 telah menerima pengaduan dari masyarakat terkait tayangan televisi yang tidak mendidik sebanyak 3.600, dan sebanyak 2000 lebih pengaduan ditujukan pada tayangan Yuk Keep Smile (teraspos.com,8 Maret 2014).

Namun, tudingan masyarakat ini ditanggapi berbeda pihak Trans TV. Mereka menilai bahwa program Yuk Keep Smile (YKS) mempunyai nilai 
positif. Menurut Public Relations Manager Trans TV, A Hadiansyah Lubis, acara tersebut justru menyentuh dan menghibur berbagai lapisan masyarakat dan selalu dinantikan kehadirannya. Bahkan, Hadiansyah mengklaim program YKS mampu memecahkan kejenuhan pemirsa atas tayangan yang ada selama ini (skalanews.com, 5 Januari 2014).

Pembelaan ini tak lain didasarkan pada jumlah rating dan share YKS yang sempat menduduki posisi 1 dengan rating 7 dan share 31 pada periode trimester akhir tahun 2013 (tabloidbintang.com, 27 Juni 2014). Tingginya jumlah rating dan share YKS berkorelasi erat dengan muatan materi yang ditawarkan kepada khalayak.

Dalam perspektif ekonomi politik media, hubungan media dengan khalayak tidak lepas dari kepentingan ekonomi dan komoditas bisnis. Posisi khalayak dalam industri televisi adalah korban yang dimanfaatkan keberadaannya, bukan saja pemilik media tetapi pengiklan. Horkheimer dan Adorno (dalam Agger, 2009, h. 198) melihat hiburan di media massa sematamata sebagai produk industri kapitalisme yang dimanipulasi dan disirkulasikan sesuai selera pasar.

Segala produk media yang dibentuk menjadi komoditas dimana nilai guna ditransformasikan ke nilai tukar ini disebut dengan istilah komodifikasi (Mosco, 2009, h. 129). Karena dalam defenisi apapun proses komodifikasi konten media ini dilakukan untuk mengakumulasi modal dan meraih profit yang sebesarbesarnya. Humor dan tarian yang semula bertujuan untuk menghibur dikomodifikasi untuk tujuan bisnis.

Apa yang dilakukan oleh televisi ini telah mencederai hak-hak publik untuk memperoleh program hiburan yang berkualitas dan mendidik sebagaimana yang diatur dalam
Undang-Undang Penyiaran Nomor 32 Tahun 2002 Pasal 4 ayat 1 yang menyebutkan bahwa: "Penyiaran sebagai kegiatan komunikasi massa mempunyai fungsi sebagai media informasi, pendidikan, hiburan yang sehat, kontrol dan perekat sosial."Selain itu juga dengan tegas telah diamanatkan dalam Pasal 36 ayat 1 dan 6 yang menyebutkan:

Ayat 1 "Isi siaran wajib mengandung informasi, pendidikan, hiburan, dan manfaat untuk pembentukan intelektualitas, watak, moral, kemajuan, kekuatan bangsa, menjaga persatuan dan kesatuan, serta mengamalkan nilainilai agama dan budaya Indonesia."

Ayat 6, "Isi siaran dilarang memperolokkan, merendahkan, melecehkan dan/atau mengabaikan nilai-nilai agama, martabat manusia Indonesia, atau me-rusak hubungan internasional."

Namun, dengan munculnya materi humor yang mencela, menyindir hingga ke dalam bentuk-bentuk yang berlebihan seperti menaburi tepung dan memukul, tatkala mengubah orientasi hiburan yang akhirnya tidak lebih dari komoditas ekonomi yang dijual kepada pengiklan. Nilai-nilai hiburan yang sejatinya adalah untuk tujuan diversi, relaksasi, stimulator dan release, malah dieksploitasi secara besar-besaran untuk kepentingan bisnis pemilik dengan mengorbankan kepentingan khalayak.

\section{Perumusan Masalah}

Media massa tidak bisa lepas dari persoalan-persoalan terkait kepentingan ekonomi dan kepentingan politik tertentu. Sebagai institusi bisnis, media massa dianggap sebagai instrumen untuk menghasilkan keuntungan bagi pemiliknya. Apa yang dilakukan oleh Trans TV pada program Yuk Keep Smile adalah cara-cara 
eksploitatif terhadap konten hiburan untuk menghasilkan profit bagi akumulasi modal pemiliknya.

Komodifikasi terhadap materimateri humor, kekerasan dan goyangan dalam program Yuk Keep Smile patut dicurigai dan dikhawatirkan penyebarannya karena terdapat beberapa slot dalam program YKS yang modifikasi dari konsep-konsep komedi dari Opera Van Java (OVJ), terutama jenis lawakan yang saling mencela (sarcasm), sindirian (satire), keanehan pada diri orang lain (ridicule), yang mengandung kekerasan yakni mengejar seseorang dan menaburi dengan tepung (chase).

Berdasarkan uraian tersebut studi ini berusaha menganalisis komodifikasi konten humor pada dua episode tayangan Yuk Keep Smile yakni konten humor para pelawak YKS pada episode 23 Januari 2014 yang menampilkan Omesh menirukan gaya dakwah para ustad, dan episode Main Tebak-tebakan yang tayang pada 23 Oktober 2014. Adapun pokok permasalahan dalam kajian ini yaitu bagaimana proses komodifikasi konten humor dalam tayangan program Yuk Keep Smile?

\section{Tinjauan Pustaka}

\section{Komodifikasi Konten Media Massa}

Ada tiga entri poin yang menjadi pintu masuk dalam Teori Ekonomi Politik Komunikasi (Mosco, 2009), yaitu: (1) komodifikasi (commodification); (2) Spasialisasi (spatialization); dan (3) strukturasi (structuration). Komodifikasi berbicara tentang bagaimana upaya mengubah segala produk dari yang hanya memiliki nilai guna ke nilai tukar. Spasialisasi berkaitan dengan sejauh mana media mampu menyajikan produknya di depan audiens dalam batasan ruang dan waktu. Pada taraf ini maka struktur kelembagaan media, menentukan perannya di dalam memenuhi jaringan dan kecepatan penyampaian produk media di hadapan khalayak. Sedangkan strukturasi terkait dengan pembentukan struktur dan agen dalam masyarakat, dan menjelaskan bagaimana relasi ide antaragen masyarakat, proses sosial dan praktik sosial.

Saat Ekonomi Politik memberikan penekanan pada bentukbentuk komodifikasi, ia terutama berusaha membongkar bagaimana relasi antara sistem produksi, distribusi dan konsumsi yang dihasilkan sebagai hasil eksploitasi yang alami. Dalam hal ini, hasil produksi yang tercipta merupakan komoditas yang digunakan untuk mengakumulasi modal.

Komoditas media ini dimulai dari konten media itu sendiri. Konten media tidak saja dalam bentuk cerita, model, kreativitas yang berada dalam satu paket program tetapi semua bentuk komoditas yang diproduksi yang selanjutnya dipasarkan kepada pengiklan untuk menghasilkan keuntungan bagi pemilik media (Mosco, 2009, h. 133).

Komoditas lainnya yang juga menjadi perhatian ekonomi politik dalam diskursus media adalah khalayak (audiance). Smythe (dalam Mosco, 2009, h.136) melihat khalayak media sebagai komoditas utama media. Komodifikasi khalayak dihasilkan dari sebuah acara yang diproduksi sedemikian rupa agar dapat menarik khayalak penonton dalam jumlah yang banyak yang kemudian dikuantifikasikan ke dalam bentuk rating. Yang dimaksud khalayak di sini adalah penononton, pendengar, user, pengguna telepon, penonton film, dan pembaca. Khalayak yang terkuantifikasi dalam rating ini yang kemudian dijual kepada pengiklan.

Pada akhirnya hubungan antara perusahaan media massa, khalayak dan 
pengiklan bersifat "reciprocal relationship". (lihat Gambar 1)

\section{Gambar 1: Proses Komodifikasi di Media Massa}

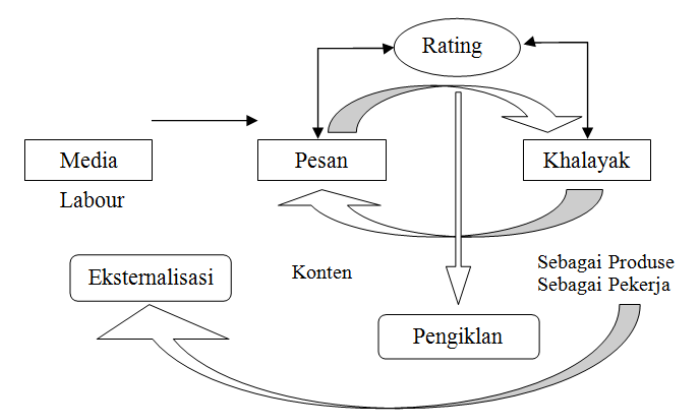

Sumber: Diadaptasi dari Buku Ekonomi Politik Komunikasi Vincent Mosco (2009)

Untuk mengetahui bagaimana proses komodifikasi berlangsung dalam program humor Yuk Keep Smile, maka perlu untuk menguraikan lebih jauh apa saja jenis humor yang dimunculkan. Analisis bentuk-bentuk humor dalam program ini penting untuk dilakukan untuk memberikan gambaran secara jelas bagaimana proses komodifikasi itu dikemas secara eksploitatif oleh televisi.

Menurut Kamus Besar Bahasa Indonesia (2008):

"Humor diartikan sesuatu yang lucu; keadaan yang menggelikan hati; kejenakaan; kelucuan. Sementara berhumor adalah menciptakan atau membuat humor, sedangkan pehumor diartikan orang yang suka melucu; pelawak".

Sedangkan Graeme Ritchie (2004, h. 6) mendefenisikan humor sebagai: "......is present throughout social conventions and cultural artefacts, and the use of humour is highly valued in interactions between people." Secara umum, Raskin (dalam Ritchie, 2004, h. 7) mengklasifikasi teori humor dalam tiga bagian yakni: "Pertama, teori mengenai pembebasan ketegangan atau pembebasan dari tekanan relief or release theories), teori superioritas dan meremehkan (superiority atau aggression theories), dan teori mengenai ketidakseimbangan, putus harapan, dan bisosiasi (incongruity theories)".

Teori superioritas dan meremehkan menjelaskan bahwa posisi yang menertawakan berada pada posisi super sedangkan objek tertawaan berada pasa posisi degradasi (diremehkan atau dihina). Sementara teori mengenai ketidakseimbangan mendasari dua situasi atau kejadian yang mustahil terjadi sekaligus. Berbeda dengan teori pembebasan ketegangan atau pembebasan dari tekanan. Jenis humor ini dapat muncul dari sesuatu kebohongan dan tipuan muslihat, bisa juga muncul dari rasa simpati. Selain itu juga isinya materi humornya bisa berupa ungkapan awam atau ungkapan-ungkapan elitis, dan dapat pula serius seperti satire dan murahan seperti humor jalanan.

Untuk menggunakan tiga teori humor tersebut dalam analisis program Yuk Keep Smile, maka perlu meminjam teknik-teknik humor yang dikemukakan oleh Arthur Asa Berger (1998). Berger (1998, h.17-18) menguraikan empat kategori humor yang dibagi ke dalam 41 teknik:

(1) Language. The humor is verbal.

Bombast, Infantilism, Irony, Misunderstanding, Pun, Repartee, Ridicule, Sarcasm, Satire, Sexual allusion, Outwitting.

(2) Logic. The humor is ideational. Irreverent behavior, Malicious pleasure, Absurdity, Coincidence, Conceptual surprise, Disappointment, Ignorance, Repetition, Rigidity.

(3) Identity. The humor is existensial.

Anthropomorphism,

Eccentricity, Embarrassment, Grotesque appearance, Imitation, Impersonation, 
Parody, Scale, Stereotype, Transformation, Visual surprise.

(4) Action. The humor is physical or nonverbal.

Clownish behavior, Clumsiness, Chase, Exaggeration, Peculiar face, Peculiar music, Peculiar sound, Peculiar voice, Slapstick, dan Speed.

\section{Analisis Teknik Humor Pada Episode Omesh "Bedakwah"}

Di acara YKS yang tayang 23 Januari 2014 silam itu, Omesh meniru gaya ceramah ustad kondang di publik. Omesh melakukan plagiat gaya $\mathrm{Aa}$ Gym, Ustad Arifin Ilham, Yusuf Mansyur, Ustand Jefry, dan Mama Dedeh (lihat Gambar 2).

Saat meniru aksi Aa Gym, Omesh bergaya dengan menyapa penonton yang datang. (liputan6.com, 4 Februari 2014).

Omesh:

Assalamualaikum,

Alhamdulilah ya bisa bertemu saudara-saudara. Subhanaallah Aa senang sekali bisa ketemu adek-adek di sini.

Proses komodifikasi dalam komunikasi melibatkan transformasi pesan menjadi produk berharga. Aa Gym adalah seorang ulama terkenal di tanah air dan memiliki pengikut yang jumlahnya sangat banyak. Dalam membawakan dakwahnya, Aa Gym memiliki gaya sendiri dan sangat khas hingga menjadi ciri khasnya. Sepintas tidak ada nilai tukar dalam hal ini. Namun, nilai guna itu kemudian berubah menjadi nilai tukar ketika kekhasan Aa Gym direproduksi oleh para pelawak terutama kru YKS untuk dijadikan konten humor. Dalam kondisi ini, Omesh sebagai pelawak berada pada posisi superioritas, dan melihat gaya $\mathrm{Aa}$ Gym sebagai sesuatu yang bisa menimbulkan tertawaan.
Hal ini bisa diperhatikan ketika mencermati mimik muka Omesh saat menirukan Aa Gym menyapa penonton. Nada suaranya dibuat rendah, pelan dan lembut secara berlebihan yang ditujukan kepada penonton perempuan. Dalam konteks ini, secara verbal, Omesh meremehkan korban dan memposisikan sebagai objek tertawaan, dan ditempatkan pada posisi degradasi (dihina), dan bukan berusaha menimbulkan simpati penonton. Nada suara yang dibuat pelan dan lembut serta ditujukan kepada penonton perempuan, menunjukkan konten humor Omesh berusaha untuk menyindir dan meremehkan Aa Gym yang melakukan poligami.

Sementara itu, penampilan Omesh mulai semakin menjadi ketika Omesh melafalkan doa yang dilakukan hanya untuk candaan. Hal ini terjadi ketika menirukan Ustad Arifin Ilham. Omesh memperagakan bagaimana Arifin Ilham menyanyikan lagu tersebut, dengan raut muka yang dipaksakan, memerah dan menunjukkan suara yang dramatis dengan menyanyikan lagu, "Astafirullah robal baroya." Konten humor ini kontan mengundang tawa para penonton di studio YKS, dan Omesh sekali lagi berada pada posisi superior dan melecehkan Arifin Ilham karena tidak mampu menyanyikan lagu tersebut dengan suara yang merdu.

Posisi superior kembali diperankan oleh Omesh pun saat menirukan gaya dakwah Ustad Yusuf Mansyur dengan memberikan pidato yang melenceng, sengaja melakukan kesalahan ketika mengatakan kata zakat dengan jaket.

Omesh: Assalmualaikum waramatulahi wabarokatu. Apa kabarnye ni, saudaraku. Namanya jakat tuh macem-macem. Ada jaket eh jakat pitrah. 


\section{Gambar 2: Omesh Menirukan Gaya}

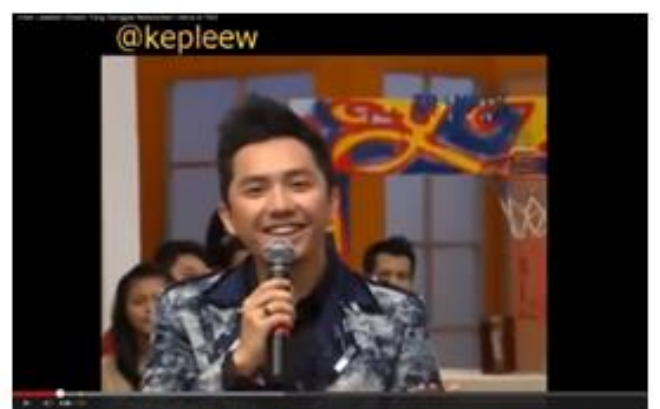

Omesh menirukan gaya Aa Gym

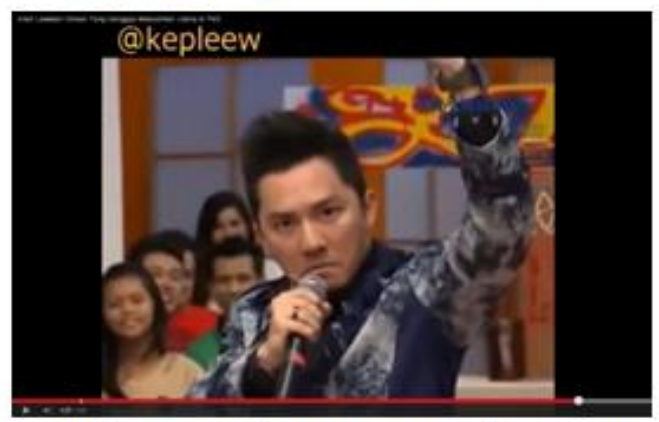

Omesh menirukan gaya YusufMansyur

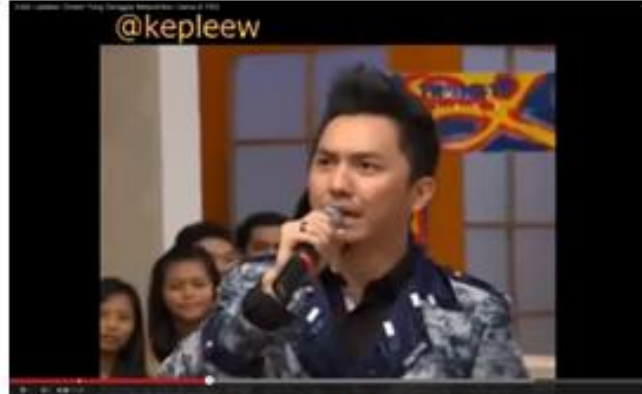

Omesh menirukan gaya Arifin Itham

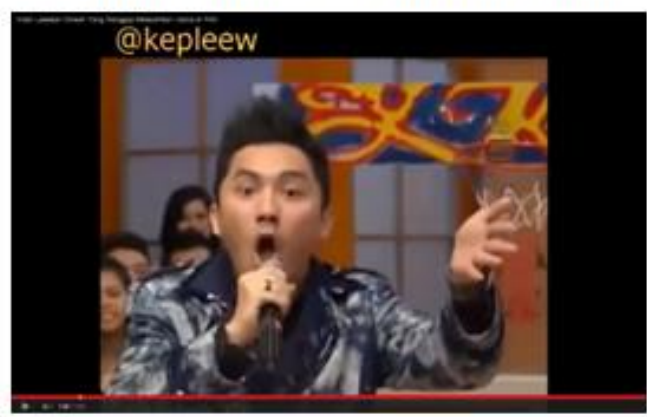

Omesh menirukan gaya Mamah Dedeh

Sumber: Keplew (diterbitkan di Youtube 5 Februari 2014)

Yusuf Mansyur adalah ustad yang berasal dari suku Betawi. Logat dan dialek Betawinya adalah salah satu yang menjadi ciri khas Yusuf Mansyur saat memberikan dakwah. Ciri lainnya adalah bahwa Yusuf Mansyur selalu menekankan tentang zakat fitrah dalam setiap dakwahnya. Dalam ceramahceramahnya yang ditayangkan di televisi juga banyak mengangkat tema tersebut. Omesh yang melihat celah tersebut, kemudian mengolahnya menjadi konten humor secara irony, yakni mengatakan sesuatu yang bermakna lain atau kebalikan dari apa yang dikatakan pada kata zakat dan jaket.

Tak hanya itu, Omesh juga mempraktekkan dua teknik sekaligus yakni teknik ridicule: bagaimana membuat orang lain menjadi terlihat bodoh secara verbal atau nonverbal, kemudian teknik satire: mempermalukan suatu hal terutama logat dan dialek Yusuf Mansyur yang kental dengan Betawi. Teknik ridicule juga dipakai untuk menirukan Mamah Dedeh. Omesh tampil dengan raut muka yang jelek, terlihat bodoh sambil mengatakan, "Mamah, curhat dong..." yang kemudian disambut tawa para penonton melihat aksi Omesh menirukan jamaah Mamah Dedeh.

\section{Analisis Teknik Humor Episode "Main Tebak Tebakan"}

Pada episode "Main Tebak Tebakan" yang ditayangkan pada 23 Oktober 2013, humor yang ditampilkan para pemain Yuk Keep Smile sudah dikategorikan ke dalam bentuk slapstick. Berger (1998:18) mengertikan slapstick, yakni: "Physical pie-in-the-face humor often involving degradation of someone's status." Pengertian lainnya diberikan oleh Stott, "Slapstick is generally understood as physical humour of a robust and hyperbolized nature where stunts, 
Gambar 3: Yuk Keep Smile
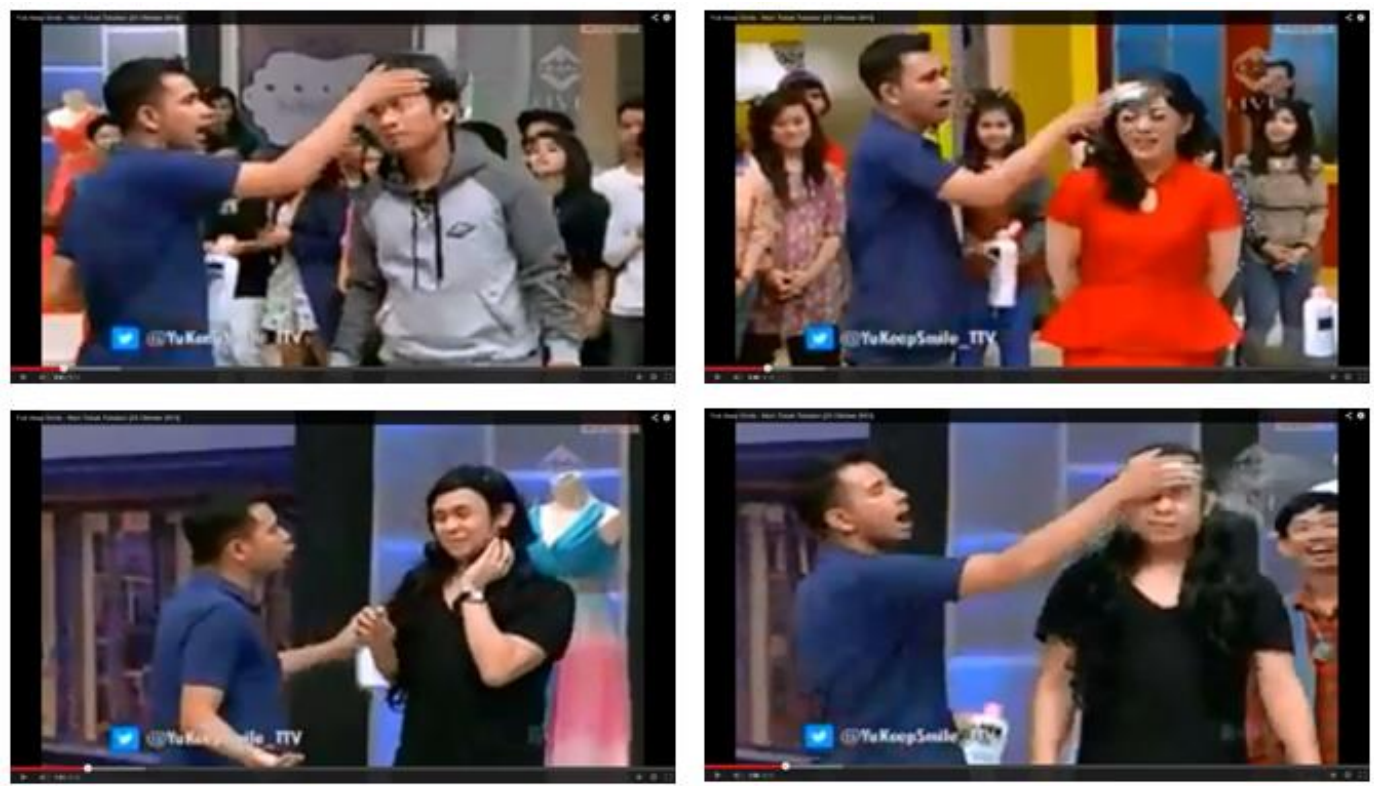

Sumber: Malik (diterbitkan di Youtube 23 Oktober 2013)

acrobatics, pain, and violence are standard features." (Stott, 2005:87).

Humor slapstick ini muncul di hampir semua dialog humor pada episode tersebut (Gambar 3). Berikut petikannya:

Scene 00.34-01.49

Rafi : Kenapa superman bisa terbang?

Deni : Karena superman... (Rafi Ahmad langsung menaburi bubuk putih ke wajah Deni tanpa perlawanan, scene 00.46)

Rafi : (menghampiri Olga pada scene 00.54)

Olga : Jangan bedakin gue, emang gue anak orok.

Rafi : Kenapa superman bisa terbang?

Olga : Aduhhh.....

Rafi : (langsung menabur bubuk putih di kening Olga)

Rafi : Kenapa superman bisa terbang, karena kalau bisa nyupir bukan supirman, eh kalau bisa nyupir bukan seperman.

(Rafi Ahmad ditaburi tepung oleh Olga, Deni, dan Soimah).

Rafi : Maksudnya gini, kalau bisa nyupir bukan superman tapi supirman. Supir mannnn. Karena kalau bisa supir truk. Supir truk nih, pacarnya nih (menunjuk Olga).
Olga : (membalas dengan memelas dan menerima olokan Rafi)

Teori superior atau juga bisa disebut teori yang menganggap remeh lawan menunjukkan dua posisi yang saling berlawanan. Satu yang berada pada posisi super, dan yang lain pada posisi degradasi (dihina). Dalam adegan humor tersebut, posisi Rafi Ahmad berada pada posisi super, dan menganggap semua pelawak lainnya (Olga, Deni, dan Soimah) pada posisi degradasi. Posisi degradasi dibuktikan pada konten humor yang digunakan oleh Rafi ketika mengajukan pertanyaan kepada pelawak lainnya. Rafi Ahmad tidak memberikan ruang kepada pelawak lainnya untuk menjawab pertanyaannya, dan semua jawaban yang diungkapkan adalah salah, sehingga Rafi memiliki kuasa untuk menaburi bubuk putih di wajah atau kepala pelawak.

Pelawak dalam menyampaikan konten humornya dipaksa untuk menarik perhatian penonton dan mengundang tawa sehebat mungkin. Karena itu, pelawak berusaha keras untuk menimbulkan bentuk humor slapstik (menaburi bubuk), dan 
menciptakan wajah yang bodoh, lugu, dan hina. Teknik humor ini disebut ignorance yakni, "Someone acts or behaves in a foolish, naive, gullible, or childish manner" (Berger, 1998:18). Hal ini bisa ditemukan dalam scene 00.54, ketika Rafi mendekati Olga, dan kemudian menunjukkan muka bodoh, lugu yang hendak dijadikan korban. Ucapan Olga, yang menyebutkan, "Jangan bedakin gue, emang gue anak orok." Adalah bentuk humor exaggeration yakni sebuah reaksi yang berlebihan atau dilebih-lebihkan untuk mengundang tawa penonton. Olga memposisikan diri rendah dengan penggunaan kata orok.

Pada scene 03.34-07.18, posisi superioritas tidak berubah. Olga tetap berada pada posisi degradasi. Karena proses komodifikasi berjalan melalui tahap per tahap, maka bukan tidak memanfaatkan scene dimana Olga menjadi bahan humor sekaligus mendapatkan bentuk lelucon yang kasar secara slapstick (lihat Gambar 4) dapat menjadi nilai tukar bagi Trans TV. Posisi degradasi ini dapat dilihat pada dialog berikut:

Rafi : Olga ngasih kita tebakan. Kalau kita bisa
jawab nanti kita bedakin rame-rame.
(Olga belum sempat berbicara, Billy
langsung membedakin Olga dan
mengatakan, "Salah.")

Rafi, Deni, Bily: Burung Beo (sambil tepung putih di kepala Olga.)

Salah seorang kru YKS, Fean muncul dalam frame, karena Olga tidak berhasil memberikan pertanyaan. Fean kemudian menuju stage sambil menunjukkan pertanyaan apa yang seharusnya disampaikan Olga. Rafi tiba-tiba mendekat dan mengatakan, "Lu (Olga) dikerjain tuh sama si Fean berarti."

Olga : Ya udah lu semua diam-diam. Biar gue kasih tebakan.

Rafi : Ya lu diam-diam, biar kita gak tahu lu kasih tebakan. Biar lu kelihatan pintar.
Pada tahap ini, teknik humor yang digunakan adalah Malicious pleasure. Berger menjelaskan teknik ini merupakan bentuk viktimisasi dengan menertawai kemalangan orang lain, atau menjadikan orang lain sebagai korban humor (Berger, 1998:18).

Sementara pada scene selanjutnya, posisi telah berubah. Posisi Olga berada pada posisi super, sementara yang berada pada posisi degradasi adalah Billy. Hal ini bisa dilihat dalam komunikasi verbal dan nonverbal Olga kepada Bily. Adapun teknik yang digunakan adalah teknik ridicule, yaitu membuat orang lain menjadi terlihat bodoh secara verbal atau nonverbal (Berger, 1998:18). Berikut petikannya:

Olga : Apa bedanya bintang dan burung hantu?

Rafi : Bintang adanya di gunung..ahh..apa sih gak tahu

Olga : Salah (sambil menaburi tepung)

Olga : Ayo apa? (kepada Deni)

Deni : Apa?

Olga : Apa ya? (lupa dengan pertanyaannya)

Deni : Tebakan, tebakan lu! Lu aja lupa apa yang lu tanya.

Bily : ...(tidak sempat menjawab)

Olga : Bang Billy...ah, salah dia gak ada otaknya.

\section{Pembahasan}

\section{Komodifikasi Humor dalam Program Yuk Keep Smile}

Berdasarkan analisis teknik humor yang diuraikan sebelumnya, maka penulis mengidentifikasi tiga hal yang dijadikan komoditas utama dalam dua episode tersebut: pertama, konten humor yang dibawakan oleh para pelawaknya lebih menekankan pada superioritas terhadap pelawak lainnya yang berada pada posisi degradasi (terhina) dengan menggunakan teknik- 


\section{Gambar 4: Yuk Keep Smile}

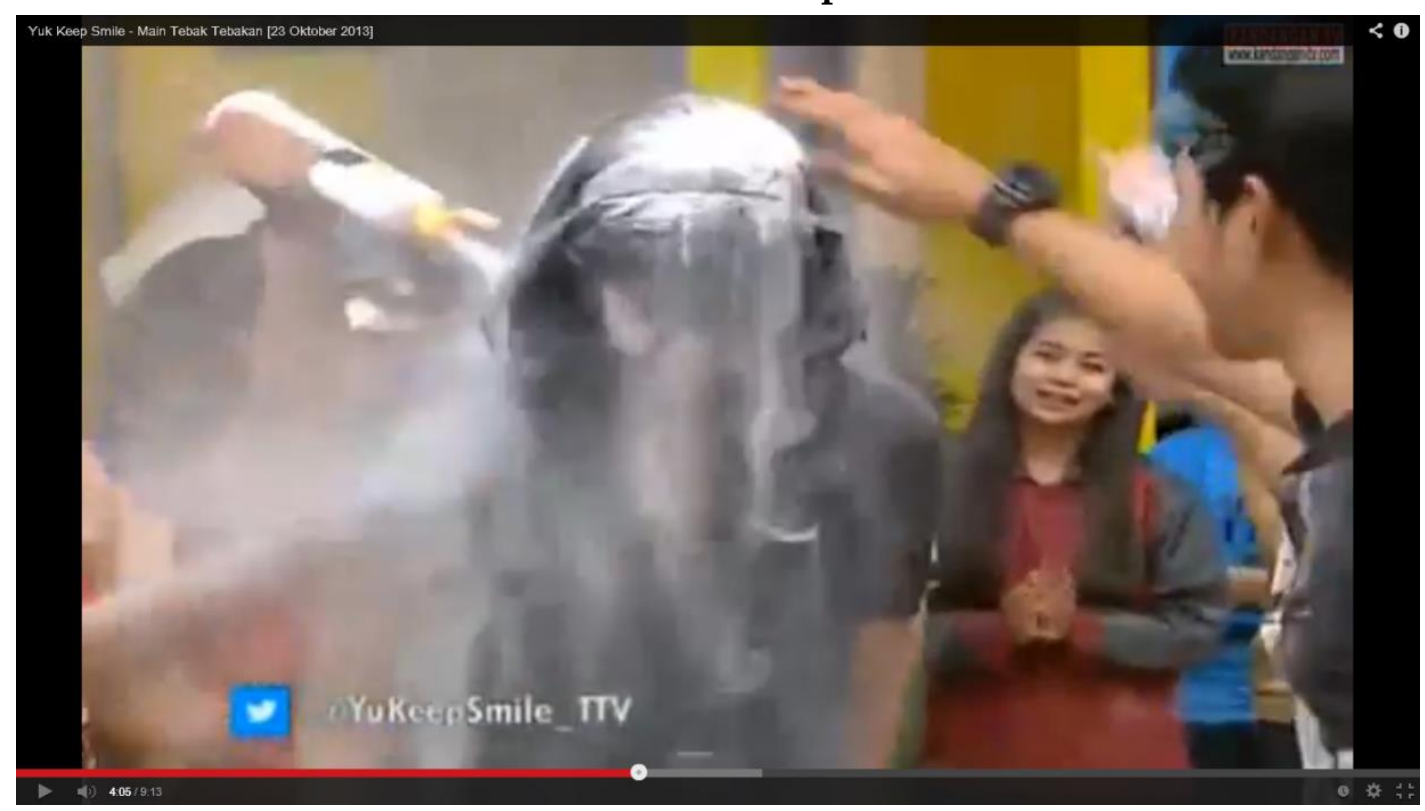

Sumber: Malik (diterbitkan di Youtube 23 Oktober 2013)

teknik humor yang sarkastik yaitu saling mencela dengan membuat orang lain menjadi terlihat bodoh secara verbal atau nonverbal (ridicule), menertawai kemalangan orang lain (malicious pleasure), atau menjadikan orang lain sebagai korban humor sebagaimana yang dilakukan oleh Omesh yang meniru gaya dakwah para ustad.

Kedua, perilaku kekerasan baik secara psikologis dan secara fisik. Kekerasan psikologis dilakukan dalam bentuk verbal misalnya dengan melecehkan, merendahkan dan hal-hal yang bisa menimbulkan kerendahan diri dari korban (Sunarto, 2009, h.57). Kekerasan psikologis ini terjadi saat para pelawak menghina Olga dan mengatainya bodoh maupun saat Olga menyebut Billy "gak ada otak". Sedangkan kekerasan fisik bisa berbentuk penyiksaan pada tubuh, penganiayaan hingga pembunuhan (Ibid,. 56). Hal ini terjadi saat pelawak menaburi tepung ke kepala pelawak lainnya (chase).

Ketiga, eksploitasi terhadap jadi diri para pelawak. Tujuan humor adalah menghibur, memberikan relaksasi dan bukan menimbulkan ketakutan. Namun, para pelawak ini harus keluar dari 'jalur' apa yang disebut sebagai 'melawak'. Mereka dieksploitasi habishabisan oleh Trans TV sebagai komoditas. Mereka tidak dinilai dari sisi kreativitas dan kualitas humor yang ditampilkan tetapi, pelawak "dipaksa" berlomba-lomba melakukan pelecehan, olokan terhadap pelawak lain. Proses ini tentu saja sangat menguras tenaga, tidak hanya para pelawak tetapi juga para kru yang berada di belakang layak. Para penonton yang ada di studio juga diatur sedemikian rupa agar memberikan respon yang berlebihan yang menandai bahwa lawakan semacam ini diminati.

Tiga komoditas yang
dieksploitasi ini telah berhasil
dikomodifikasi oleh Trans TV untuk
meraup keuntungan sangat besar.
Bagaimana membuktikannya? Hal ini
bisa dilihat dari jumlah rating dan share
yang diperoleh YKS. Berdasarkan hasil
riset Nielsen pada kuartal ketiga 2013,
menyebutkan bahwa ada sebanyak1,868
dari 48,573 juta orang berusia di atas 5
tahun yang tinggal di 10 kota besar yang


menonton YKS (pada pukul 20.0023.30/20.00-22.30/07.30-08.30). Di jam tayang itu, YKS sanggup meraih share penonton sebesar 17,7 persen dan rating 3,8 (Wulandari, 2014). Share dan rating yang sebesar itu menunjukkan bahwa program YKS mampu menarik penonton dalam jumlah yang besar.

Tak hanya rating dan share yang tinggi, kondisi ini juga telah menghantarkan Trans TV pada posisi pertama. "Acara YKS, telah menempatkan stasiun televisinya, TransTV, di puncak rating selama tujuh hingga delapan bulan terakhir. Padahal, selama ini, media milik Chairul Tanjung tersebut cuma mampu bertengger di posisi 4, kalah bersaing dengan stasiun TV dari MNC Group," Rahmat Arifin, Ketua Bidang Isi Siaran Komisi Penyiaran Indonesia (Bisnis.com, 26 Januari 2014).

Hingga Maret 2014, dari antara program-program Trans TV atau pun Trans 7, hanya program YKS yang mampu menghasilkan rating dan share yang tertinggi yaitu sebesar 3,5 dan 15,8 (Table 1) karena itu YKS menjadi program unggulan dan merupakan program yang memperoleh iklan terbanyak (Trans TV, 2014). Namun demikian, sebagaimana pola program hiburan televisi yang memperoleh rating dan share yang tinggi, maka akan memunculkan imitasi-imitasi program tersebut di televisi lainnya seperti Fesbuker di ANTV, Eatbulaga di SCTV atau D't3rong Show di Indosiar (lihat Table 2). Program-program itu meski serupa tapi tak sama tetapi tujuannya sama yaitu eksploitasi konten hiburan untuk meraih rating yang sebesarbesarnya.

Kendati telah lengser sebagai program dengan rating dan share tertinggi, YKS masih tetap berada di tiga besar program yang paling diminati penonton setelah D Academy dan D't3rong Show yang ditayangkan oleh
Indosiar dengan perolehan rating 3,5 dan share 15,8. Sementara perolehan rating seluruh stasiun televisi, Trans TV berada di urutan keempat. Rating dan share terbesar disumbangkan oleh program acara Yuk Keep Smile.

\section{Tabel 1: Rating dan Share Program Televisi (30/3/2014-5/4/2014)}

\begin{tabular}{|l|l|c|c|}
\hline \multicolumn{1}{|c|}{ Program } & $\begin{array}{c}\text { Stasiun } \\
\text { Televisi }\end{array}$ & $\begin{array}{c}\text { TV } \\
\text { Rating }\end{array}$ & $\begin{array}{c}\text { TV } \\
\text { Share }\end{array}$ \\
\hline D Academy & Indosiar & 6,0 & 29,4 \\
\hline $\begin{array}{l}\text { D't3rong } \\
\text { Show }\end{array}$ & Indosiar & 4,6 & 21,8 \\
\hline YKS & Trans TV & 3,5 & 15,8 \\
\hline $\begin{array}{l}\text { Pashmina } \\
\text { Aisha }\end{array}$ & MNC TV & 3,6 & 15,4 \\
\hline $\begin{array}{l}\text { Ayah } \\
\text { Mengapa Aku } \\
\text { Berbeda }\end{array}$ & RCTI & 3,7 & 15,4 \\
\hline $\begin{array}{l}\text { Tukang Bubur } \\
\text { Naik Haji }\end{array}$ & RCTI & 3,9 & 15,2 \\
\hline
\end{tabular}

Sumber: Trans TV (2014)

Animo masyarakat yang masih sangat tinggi terhadap program YKS ini, semakin dimanfaatkan oleh pihak produksi untuk membuat acara-acara yang serupa menambah pundi-pundi keuntungan dan semakin menegasikan tujuan dan esensi nilai hiburan itu sendiri. Mereka mengikuti sekaligus menyetir selera masyarakat secara hegemonik untuk melanggengkan siklus sistem produksi-distribusikonsumsi dari program tersebut

Inilah yang disebut Mosco (2009, h. 136) sebagai komodifikasi khalayak, yang merupakan komoditas primer yang bisa menciptakan surplus produksi melalui iklan. Program media yang semakin diminati khalayak akan digiring untuk diikat dan secara terus menerus dikokohkan dan dipertahankan. Jumlah khalayak yang terkuantifikasi dalam rating dan share ini yang nantinya dijual kepada 
Tabel 2: Perolehan Rating dan Share Stasiun Televisi

\begin{tabular}{|c|c|c|c|c|c|c|c|c|c|c|c|c|c|}
\hline \multirow{4}{*}{$\mathrm{No}$} & \multicolumn{13}{|c|}{$\begin{array}{l}\text { TOTAL AVERAGE ALL STATION } 7 \text { DAYS (JKT-BDG-SBY) } \\
\qquad 30 \text { Maret - 5 APRIL } 2014\end{array}$} \\
\hline & & \multicolumn{2}{|c|}{ Total Individuals } & \multicolumn{2}{|c|}{ SES A } & \multicolumn{2}{|c|}{ SES B } & \multicolumn{2}{|c|}{ SES C } & \multicolumn{2}{|c|}{ SES AB } & \multicolumn{2}{|c|}{ SES ABC } \\
\hline & & 13 & 14 & 13 & 14 & 13 & 14 & 13 & 14 & 13 & 14 & 13 & 14 \\
\hline & Channel/Variable & Rating & Share & Rating & Share & Rating & Share & Rating & Share & Rating & Share & Rating & Share \\
\hline 1 & IVM & 17,7 & 15,7 & 17,4 & 14,2 & 14,2 & 14,4 & 18,3 & 16,1 & 15,2 & 14,3 & 17,5 & 15,6 \\
\hline 2 & SCTV & 13,5 & 14,4 & 13,3 & 13,5 & 13,9 & 14,8 & 14,0 & 14,9 & 13,7 & 14,4 & 13,9 & 14,8 \\
\hline 3 & RCTI & 13,7 & 14,3 & 10,5 & 13,7 & 15,8 & 16,4 & 13,2 & 13,5 & 14,1 & 15,6 & 13,5 & 14,1 \\
\hline 4 & TRANS TV & 11,6 & 11,6 & 10,5 & 10,3 & 11,9 & 11,5 & 11,9 & 11,8 & 11,5 & 11,1 & 11,8 & 11,6 \\
\hline 5 & ANTV & 8,4 & 9,3 & 6,6 & 6,6 & 8,0 & 8,6 & 8,0 & 9,1 & 7,5 & 8,0 & 7,9 & 8,8 \\
\hline 6 & TRANS 7 & 8,8 & 9,0 & 9,4 & 9,6 & 8,2 & 8,0 & 9,2 & 9,5 & 8,6 & 8,5 & 9,1 & 9,2 \\
\hline 7 & MNC TV & 9,0 & 8,3 & 4,7 & 4,9 & 7,8 & 6,4 & 8,7 & 8,5 & 6,8 & 6,0 & 8,3 & 7,8 \\
\hline 8 & GTV & 5,4 & 6,1 & 6,0 & 8,2 & 5,6 & 6,0 & 5,4 & 5,9 & 5,8 & 6,6 & 5,5 & 6,1 \\
\hline 9 & TVONE & 3,9 & 3,4 & 8,1 & 7,6 & 5,8 & 4,2 & 3,4 & 3,1 & 6,6 & 5,2 & 4,2 & 3,6 \\
\hline
\end{tabular}

Sumber: Trans TV (2014)

pengiklan (ibid,. 137). Karena itu semakin tinggi minat khalayak terhadap sebuah program, maka akan semakin tinggi ratingnya. Rating di sinilah yang menjadi komoditas intrinsik dari khalayak (ibid., 141). Dalam hal ini khalayak atau penonton YKS adalah konsumen media yang menikmati hasilhasil produksi dari industri media yang dikomodifikasi menjadi rating dan kemudian dijual kepada pengiklan.

\section{Simpulan}

Dominasi program hiburan dalam tayangan televisi ditengarai sebagai salah satu strategi yang ditempuh oleh banyak stasiun televisi untuk menghasilkan keuntungan (revenue) yang sebesar-besarnya demi akumulasi kapital pemilik media. Program-program hiburan televisi tersebut dikemas dalam logika kapitalistik sebagai sebuah komoditas yang bernilai jual.

Komodifikasi konten humor dalam program Yuk Keep Smile memberikan gambaran yang jelas bagi kita bahwa institusi media adalah institusi yang berjalan dalam logika bisnis yang selalu mengikuti selera pasar dan berorientasi pada profit. Yuk Keep Smile sebetulnya bukan program baru di Trans TV melainkan metamorfosis dari program Yuk Kita Sahur yang juga merupakan program imitasi dari Opera Van Java dalam sejumlah plotnya. Hal ini mengindikasikan bahwa programprogram hiburan semacam ini dilahirkan semata-semata mengulang kesuksesan perolehan rating dan share yang pernah diraih.

Ada tiga komoditas utama dalam program YKS berdasarkan hasil analisis kajian ini: pertama, materi humor yang merendahkan dan melecehkan; kedua, kekerasan psikologis dan kekerasan fisik; ketiga, eksploitasi terhadap para pelawak. Ketiga konten humor tersebut juga bukan sesuatu yang baru karena di hampir semua episode hal tersebut dapat ditemukan. Konten-konten humor dalam program Yuk Keep Smile dikomodifikasi dari yang semula hanya memiliki nilai guna menjadi barang dagangan. 
Kekuasaan (power) yang dimiliki oleh televisi mampu memengaruhi bahkan memanipulasi khalayak dengan tayangan-tayangan tersebut. Khayalakkhalayak ini sebagaimana disampaikan oleh Smythe merupakan komoditas primer bagi media yang dikuantifikasi ke dalam angka-angka rating. Karena itu semakin banyak penonton yang menggemari program YKS maka akan semakin tinggi rating yang dihasilkan, dan semakin mengokohkan eksistensi tayangan.

\section{Daftar Rujukan}

Anastasya, Sicilia. 2013. Teknik-Teknik Humor Dalam Program Komedi di Televisi Swasta Nasional Indonesia. Jurnal Komunikasi, Universitas Kristen Petra, Surabaya.

Berger, Arthur. 1998. An Anatomy of Humor. United States of America: Transaction Publishers.

Departemen Pendidikan Nasional. 2008. Kamus Besar Bahasa Indonesia. Edisi Keempat. Jakarta: PT Gramedia Pustaka Utama

Mosco, Vincent. 2009. The Political Economy of Communication. London: SAGE Publications, Thousand Oaks.

McQuail, Denis. 2011. Mass Communication Theory, (penerj: Putri Iva Izzati). Jakarta: Salemba Humanika.

Ritchie, Graeme. 2004. The Linguistic Analysis of Jokes. New York: Routledge.

Ruben. Brent D, \& Stewart. Lea P. 2006. Communication and Human Behavior. Fitfth Edition. USA: Pearson Education, Inc.

Stott, Andrew. 2005. Comedy: The New Critical Idiom. New York: Routledge.

Sunarto. 2009. Televisi, Kekerasan, E Perempuan. Jakarta: Kompas Media Nusantara.

Trans TV. 2014. Daily Program Comparison All Station Week 1414: Target Audience All 5+ City : Jakarta, Bandung, Surabaya. Saturday (05/04/2014).

\section{Media Online}

Alfian, Rifqi. (2013, diakses 21 Juni 2014). @TRANSTV_CORP: Segera Hentikan Penayangan YKS. (http://www.change.org/id/petisi/transtv-corp-segerahentikan-penayangan-yks).

Bisnis.com (2014, diakses 22 Juni 2014). Tayangan TV Adu Kreatif Demi Rating. (http://m.bisnis.com/bisnis-indonesia/read/20140126/250/199369/tayangantv-adu-kreatif-demi-rating).

Keplew. (2014, diakses 22 Juni 2014). Inilah Lawakan Omesh Yang Dianggap Melecehkan Ulama di YKS. (http:// www.youtube.com/watch?v=5OWjHnwCpxE).

Koranjakarta.com. (2014, diakses 22 Juni 2014). The Power of Rating. (http://www.koran-jakarta.com/?14021-the\%20power\%20of\%20rating)

Liputan6.com. (2014, diakses 22 Juni 2014). Omesh Dihujat Akibat Lecehkan Ulama. (http://showbiz.liputan6.com/read/817608/omesh-dihujat-akibat-lecehkanulama).

Malik Jie Punya. (2013, diakses 22 Juni 2014). Yuk Keep Smile - Main Tebak Tebakan [23 Oktober 2013]. (http://www.youtube.com/watch?v=T-NPLrO8Xx0). 
Merdeka.com (2014, diakses 22 Juni 2014). 4 Kontroversi Yang Muncul di Trans TV. (http://www.merdeka.com/peristiwa/4-kontroversi-yang-muncul-dalamacara-yks-trans-tv.html).

Okezone.com. (2013, diakses 22 Juni 2014). KPI Terima Banyak Aduan Goyang Oplosan $Y K S$

(http://celebrity.okezone.com/read/2013/12/31/533/919872/kpi-terimabanyak-aduan-goyang-oplosan-yks).

Solopos.com (2013, diakses 21 Juni 2014). 21.000 Orang Tanda Tangani Petisi Yuk Keep Smile Dihentikan. http://www.solopos.com/2014/01/03/yks-transtv-21-000orang-tanda-tangani-yuk-keep-smile-dihentikan-479125

Tabloidbintang.com (2014, diakses 22 Juni 2014). Rating YKS Belakangan Tidak Segemilang Awal Penayangannya. (http:/ / www.tabloidbintang.com/articles/film-tv-musik/ulasan/9419-ratingyks-belakangan-tidak-segemilang-awal-penayangannya)

Teraspos.com (2014, diakses 22 Juni 2014). KPI Terima 3600 Pengaduan. (http:// www.teraspos.com/read/2014/03/09/83017/kpi-terima-3600pengaduan).

Wulandari, Dwi (2014, diakses 22 Juni 2014). Cara Trans Media Hindari Kanibalisasi. (http:/ / mix.co.id/brand-communication/media/cara-trans-media-hindarikanibalisasi/) 